\title{
OBSERVATIONS ON THE CONTENT OF ATP AND ADP IN BULL SPERMATOZOA USING THE FIREFLY LUCIFERASE SYSTEM
}

\author{
D. E. BROOKS \\ A.R.C. Unit of Reproductive Physiology and Biochemistry, \\ University of Cambridge*
}

(Received 4th August 1970)

The development of a method to measure small amounts of nucleotides would be of considerable value in experiments concerned with metabolism in mammalian spermatozoa. As the adenine nucleotides have been shown to be the predominant nucleotides in mammalian spermatozoa (Brooks, 1970), measurement of ATP and ADP by the luciferin-luciferase system appeared to be a method ideally suited to this purpose.

Ejaculated bull semen, collected by artificial vagina, was used in the present work. The measurement of ATP was carried out in a Packard Model 3380 liquid scintillation spectrometer calibrated according to Stanley \& Williams (1969). The phosphate buffer described by these workers was altered to include 2 mm-EDTA and 2 mM-2-mercaptoethanol. In addition, the luciferinluciferase preparation made up in arsenate buffer was incubated with apyrase to reduce background luminescence (Lyman \& DeVincenzo, 1967). ADP was measured as the increase in luminescence after conversion to ATP (Holmsen, Holmsen \& Bernhardsen, 1966). The conversion was achieved by incubating sample aliquots in vials in which the phosphate buffer contained $2 \mu \mathrm{l}$ each of pyruvate kinase suspension (The Boehringer Corporation) and $10 \mathrm{~mm}$-phosphoenolpyruvate. The conversion was complete in $10 \mathrm{~min}$ at room temperature, and finally the enzyme was inhibited by addition of the arsenate buffer.

Preliminary experiments were carried out to compare two methods of nucleotide extraction as applicable to small samples $(1 \mathrm{ml})$ of semen. (i) The semen was added directly to $1 \mathrm{ml}$ of ice-cold $20 \%$ trichloroacetic acid (TCA) in a centrifuge tube held on a rotamixer to ensure instant mixing. (ii) The semen was frozen by dripping into liquid $\mathrm{N}_{2}$ and then ground to a fine powder with $1 \mathrm{ml}$ of frozen $20 \%$ TCA in a porcelain mortar. The grinding was continued until the material thawed, the slurry being transferred with water washings to a centrifuge tube. Samples extracted by either method were made up to about $7 \mathrm{ml}$ with water in the centrifuge tube and were then spun at $35,000 \mathrm{~g}$ for 5 min at $-2^{\circ} \mathrm{C}$. The supernatants were removed, neutralized with $\mathrm{N}-\mathrm{NaOH}$ until faintly pink to phenolphthalein and made up to $10 \mathrm{ml}$ with water. The samples were frozen at $-15^{\circ} \mathrm{C}$ until analysis, usually on the same day. The

* Postal address: Animal Research Station, 307 Huntingdon Road, Cambridge CB3 0JQ, U.K. 
recovery of radioactivity from the addition of $0.025 \mu \mathrm{c}$ of $\left[{ }^{14} \mathrm{G}\right] \mathrm{ATP}$ was $99.0 \pm 0.7$ for method (i) and $94.4 \pm 1 \cdot 1$ for method (ii); there was no significant difference between ATP and ADP contents after extraction by the two methods when corrected for these recoveries. In general, method (i) was adopted due to its greater simplicity.

The experiment depicted in Text-fig. I was carried out to examine the effect of washing spermatozoa by centrifugation and resuspension in fresh medium, a process frequently adopted to remove seminal plasma from spermatozoa. Analysis of samples not resuspended was achieved for 1-ml aliquots by centrifuging in small thin-walled glass tubes which were frozen in liquid $\mathbf{N}_{2}$ after the centrifuge had stopped. When frozen, the glass was easily fractured and removed from the sample pellet which was then extracted by

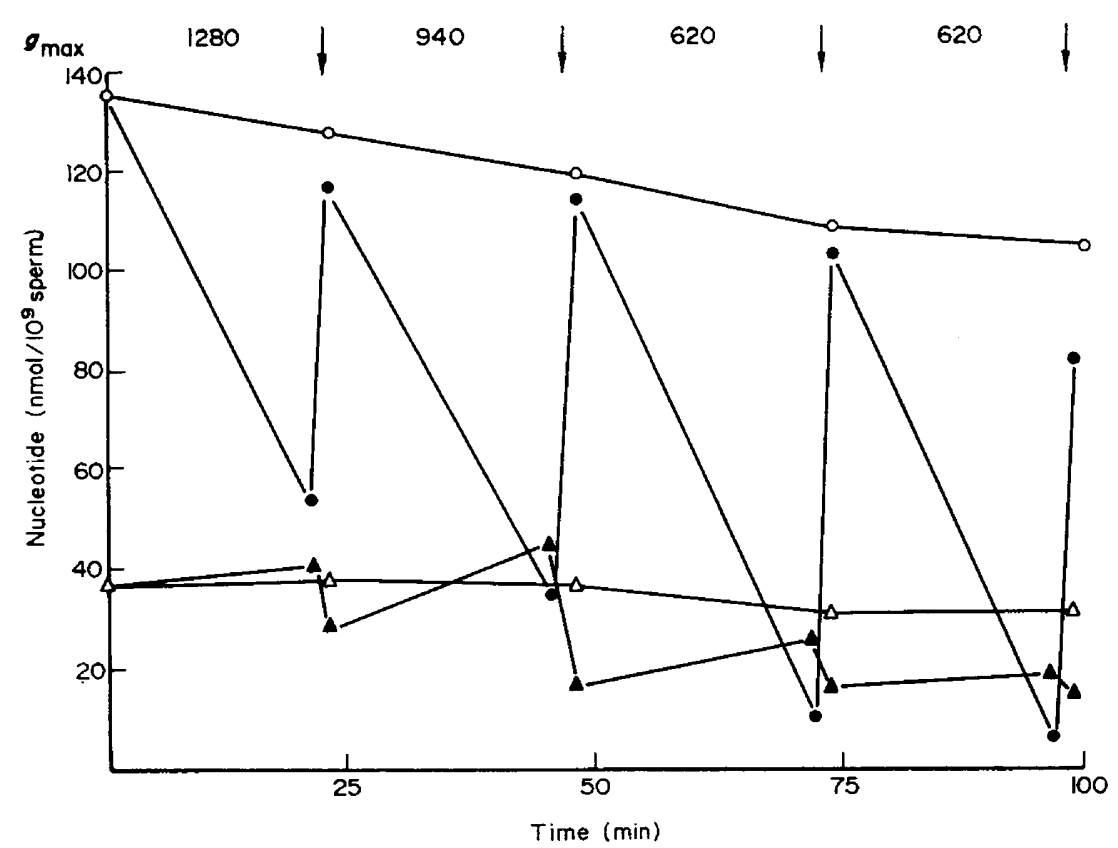

TEXT-Fic. 1. Effect of four successive centrifugations (15 min) and resuspensions (to original volume) of bull spermatozoa in $150 \mathrm{~mm}-\mathrm{NaCl}$, on their content of ATP and ADP. The arrows represent the points of resuspension. O, ATP; $\triangle$, ADP content of control sample left undisturbed in a tube at room temperature. $\bullet$, ATP; $\triangle$, ADP content of centrifuged and resuspended samples.

method (ii), as were all samples in this experiment. Four main points were evident from the results: (a) centrifugation caused a marked decrease in the ATP content; (b) rapid recovery (less than $2 \mathrm{~min}$ ) was achieved by resuspension in fresh medium by aspiration with a Pasteur pipette; (c) despite the fact that exogenous substrate is largely removed after two washings, recovery was still high in resuspensions 3 and 4; (d) the dramatic fall in ATP content upon centrifugation was accompanied by an increase in ADP content.

It seemed likely that the reason for these large changes in ATP content could be due to one or more of the following factors: the availability either of 
oxygen or of a glycolysable substrate; or the buffering capacity of the medium. The necessity of oxygen for the rise in ATP content on resuspension of cells washed in diluent without sugar follows from the demonstration that no recovery occurred when the cells were resuspended into fresh medium containing an inhibitor of oxidative phosphorylation, either $1 \mathrm{~mm}$-dinitrophenol or $10 \mathrm{~mm}$-cyanide brought to $\mathrm{pH} 7$. In an attempt to establish the contribution of the other factors towards the depression of ATP during centrifugation, the series of four experiments depicted in Text-fig. 2 was carried out. Semen was washed three times by four-fold dilution in diluent and then resuspended to the original volume. Aerobic samples were aspirated with air from a Pasteur pipette for $1 \mathrm{~min}$ every $15 \mathrm{~min}$ (starting at $7 \mathrm{~min}$ ); anaerobic samples were
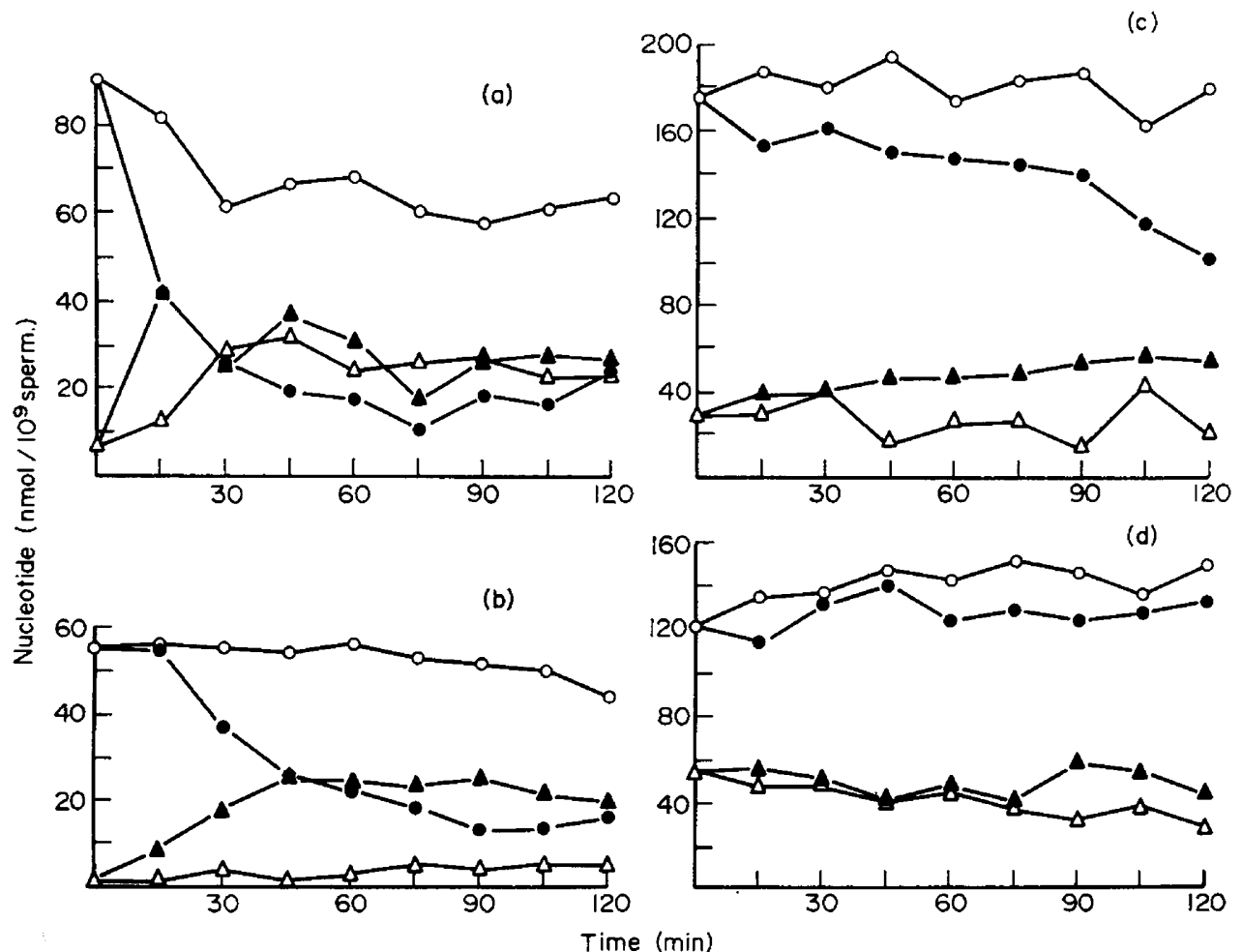

Text-Fig. 2. Effect of availability of oxygen and glycolysable substrate and diluent buffering-capacity on the ATP and ADP content of bull spermatozoa. $\odot, A T P ; \triangle$, ADP content of aerobic samples; $\bullet$ ATP; $\mathbf{A}$, ADP content of anaerobic samples in (a) 150 $\mathrm{mM}-\mathrm{NaCl}$, (b) $150 \mathrm{~mm}-\mathrm{NaCl}+22 \mathrm{~mm}$-fructose, (c) buffered diluent without fructose, and (d) buffered diluent with $22 \mathrm{~mm}$-fructose.

taken from a Thunberg tube evacuated and gassed with $\mathrm{N}_{2}$. The buffered diluent was the sodium-potassium diluent used by White (1953). Although the four graphs are not strictly comparable, as the experiments were carried out on separate samples of semen, the main effects of the different treatments are clearly visible. In all diluents, anaerobic conditions produced a decrease in ATP and an increase in ADP content. The effect was most marked in the diluent containing no sugar and with no buffering capacity (Text-fig. 2a). 
Incubation in a buffered diluent offset the effect of anaerobic conditions only to a limited extent (Text-fig. 2b); however, the inclusion of fructose was very effective in maintaining a high ATP/ADP ratio (Text-fig. 2c), especially in the buffered diluent (Text-fig. 2d) where lactic acid production would not cause a substantial fall in $\mathrm{pH}$.

This study demonstrates that anaerobiosis, particularly in the absence of sugar, causes a marked decline in the ATP content of spermatozoa (Text-fig. 2). Most likely, the dramatic fall in ATP content which occurs when spermatozoa are packed by centrifugation (Text-fig. 1) can be explained by the fact that the packed cells are effectively separated from the diluent and therefore suffer an acute lack of oxygen and glycolysable substrate.

\section{REFERENCES}

BRooks, D. E. (1970) Acid-soluble phosphorus compounds in mammalian semen. Biochem. 7. 118, 851. Holmsen, H., Holmsen, I. \& Bernhardsen, A. (1966) Microdetermination of adenosine diphosphate and adenosine triphosphate in plasma with the firefly luciferase system. Analyt. Biochem. 17, 456.

Lyman, G. E. \& DeVincenzo, J. P. (1967) Determination of picogram amounts of ATP using the luciferin-luciferase enzyme system. Analyt. Biochem. 21, 435.

Stanley, P. E. \& Williams, S. G. (1969) Use of the liquid scintillation spectrometer for determining adenosine triphosphate by the luciferase enzyme. Analyt. Biochem. 29, 381.

WhITE, I. G. (1953) Metabolic studies of washed and diluted ram and bull spermatozoa. Aust. F. biol. Sci. 6, 706. 